DOI :10.31357/fapsmst.2015.00525

\title{
Quality Variation of Selected Imported Ration
}

\section{Ingredients}

\author{
By
}

\section{Dinamuni Shanika Geethani Mendis}

Thesis submitted to the University of Sri Jayewardenepura as a partial fulfillment of the requirement for the award of the Master of Science in Food Science and Technology. 


\section{Declaration}

The work described in this thesis was carried out by me under the supervision of Dr. R.A.U.J. Marapana and a report of this has not been submitted in whole or part to any university or any other institution for another Degree.

Sluder

Dinamuni Shanika Geethani Mendis

Date: $8 / 12 / 2015$ 


\section{Declaration}

I certify that the above statement made by the candidate is true and that this thesis is suitable for submission to the University for the purpose of evaluation

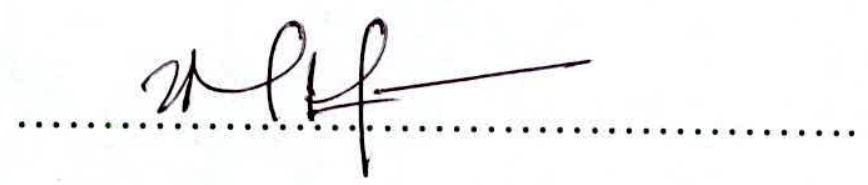

Dr. R.A.U.J. Marapana

Date: $10 \cdot 12 \cdot 2015$ 


\section{TABLE OF CONTENTS}

Page

List of Tables vi

Acknowledgement vii

Abstract viii

CHAPTER 1 : INTRODUCTION 1

CHAPTER 2 : LITERATURE REVIEW 2

2.1 Components of Poultry Diets 2

2.2 Energy 3

2.2.1 Energy Terminology 3

2.3 Proteins and Amino acids 5

2.3.1 Variations in Requirements $\quad 6$

2.4 Fat 6

$\begin{array}{ll}2.5 \text { Minerals } & 7\end{array}$

2.6 Vitamins 8

$\begin{array}{ll}2.7 \text { Water } & 9\end{array}$

2.8 Other nutrients and additives $\quad 9$

$\begin{array}{ll}2.9 \text { Raw Materials } & 10\end{array}$

$\begin{array}{ll}2.10 \text { Soya Bean Meal } & 10\end{array}$

$\begin{array}{ll}2.10 .1 \text { Description } & 10\end{array}$

2.10.2 Distribution

2.10.3 Nutritional attributes $\quad 11$

2.10.4 Potential constraints $\quad 12$ 
2.11 Fish Meal 13

$\begin{array}{ll}\text { 2.11.1 Description } & 13\end{array}$

2.11.2 Distribution 14

$\begin{array}{ll}\text { 2.11.3 Nutritional attributes } & 14\end{array}$

$\begin{array}{ll}\text { 2.11.4 Potential constraints } & 14\end{array}$

$\begin{array}{ll}2.11 .5 \text { Poultry } & 15\end{array}$

$\begin{array}{ll}2.12 \text { Wheat (general) } & 15\end{array}$

$\begin{array}{ll}\text { 2.12.1 Description } & 15\end{array}$

$\begin{array}{ll}\text { 2.12.2 Distribution } & 16\end{array}$

$\begin{array}{ll}\text { 2.12.3 Nutritional attributes } & 16\end{array}$

$\begin{array}{ll}\text { 2.12.4 Potential constraints } & 17\end{array}$

$\begin{array}{ll}2.12 .5 \text { Poultry } & 17\end{array}$

$\begin{array}{ll}2.13 \text { Palm Oil } & 18\end{array}$

$\begin{array}{ll}\text { 2.13.1 Description } & 18\end{array}$

2.13.2 Distribution 19

$\begin{array}{ll}\text { 2.13.3 Quality Control } & 19\end{array}$

CHAPTER 3 : MATERIALS AND METHODS 22

$\begin{array}{ll}\text { 3.1 Methodology } & 22\end{array}$

3.1.1 Study Location $\quad 22$

3.1.1.2 Selection of Raw Materials $\quad 22$

3.1.2 Sampling methods $\quad 24$

3.1.2.2 Preparing the sample $\quad 24$

3.1.2.3 Tested Parameters $\quad 24$ 
3.2.1 Determination of Moisture

3.2.1.1 Procedure

3.2.2 Determination of Crude Protein

3.2.2.1 Apparatus/ Equipment

3.2.2.2 Reagents

3.2.2.3 Procedure

3.2.3 Determination of Crude Fat

3.2.3.1 Apparatus/ Equipment

3.2.3.2 Reagents

3.2.3.3 Procedure

3.2.4 Determination of Crude Fibre

3.2.4.1 Apparatus/ Equipment

3.2.4.2 Reagents

3.2.4.3 Procedure

3.2.5 Determination of Ash

3.2.5.1 Apparatus/ Equipment

3.2.5.2 Procedure

3.2.6 Determination of Calcium

3.2.6.1 Reagents

3.2.6.2 Procedure

3.2.7 Determination of Phosphorous 
3.2.8 Determination of Sugar and Starch

3.2.8.1 Apparatus/ Equipment

3.2.8.2 Reagents

3.2.8.3 Procedure

3.2.9 Determination of Soluble Protein in SBM

3.2.9.1 Reagents

3.2.9.2 Procedure

3.2.10 Determination of Salt

3.2.10.1 Reagents

3.2.10.2 Procedure

3.2.11 Determination of Pepsin Digestibility

3.2.11.1 Apparatus/ Equipment

3.2.11.2 Reagents

3.2.11.3 Procedure

3.2.12 Determination of Iodine Value

3.2.12.1 Apparatus/ Equipment

3.2.12.2 Reagents

3.2.12.3 Procedure

3.2.13 Determination of Free Fatty Acids

3.2.13.1 Reagents

3.2.13.2 Procedure

3.2.14 Determination of Peroxide Value 
3.2.15 Determination of Impurities $\quad 48$

3.2.15.1 Apparatus/ Equipment 48

$\begin{array}{ll}3.2 .15 .2 \text { Reagents } & 49\end{array}$

$\begin{array}{ll}\text { 3.2.15.3 Procedure } & 49\end{array}$

3.2.16 Determination of Unsap Value $\quad 49$

3.2.16.1 Apparatus/ Equipment $\quad 50$

$\begin{array}{ll}3.2 .16 .2 \text { Reagents } & 50\end{array}$

$\begin{array}{ll}\text { 3.2.16.3 Procedure } & 50\end{array}$

3.3 Statistical Data Analysis $\quad 52$

CHAPTER 4 : RESULTS AND DISCUSSION 53

4.1 Soya Bean Meal 53

4.2 Fish Meal $\quad 55$

4.3 Wheat Flour $\quad 58$

$\begin{array}{ll}\text { 4.4 Palm Oil } & 60\end{array}$

CHAPTER 5 : CONCLUSION

$\begin{array}{lc}\text { REFERENCES } & 63\end{array}$

$\begin{array}{ll}\text { APPENDICES I - LVII } & \text { IPI }\end{array}$ 


\section{List of Tables}

Table. 4.1 : Proximate composition of Soya Bean Meal 53

Table. 4.2 : Proximate composition of Fish Meal 55

Table. 4.3 : Proximate composition of Wheat Flour 58

Table. 4.4 : Quality of Palm Oil $\quad 60$ 


\section{ACKNOWLEDGEMENTS}

Firstly, I make this an opportunity to express my sincere appreciation and gratitude to my supervisor, Dr. R.A.U.J. Marapana, Senior Lecturer, Department of Food Science and Technology, Faculty of Applied Sciences, University of Sri Jayewardenepura for his invaluable guidance throughout my research.

Further I wish to express my thanks to the management of Ceylon Grain Elevators PLC, Colombo for providing me chemicals, consumables and instrumental facilities for my research. Special thanks go to all the lecturers and the staff members of Department of Food Science and Technology, Faculty of Applied Sciences, University of Sri Jayewardenepura for all the support provided throughout the two years as a postgraduate student.

I am very grateful to my parents, friends and my colleagues who gave me the necessary encouragement and support whenever required. 


\title{
Quality variation of selected imported ration ingredients
}

\section{Dinamuni Shanika Geethani Mendis}

\begin{abstract}
Imported and local raw materials are used in animal feeds. Their quality is very important to produce a quality final product. By knowing the nutrient contents of raw materials, producers can identify the deficient nutrients that need to be supplemented. Poultry diets are composed primarily of a mixture of several feedstuffs such as cereal grains, soybean meal, animal by-product meals, fats, and vitamin and mineral premixes.

In this study, concentrate feedstuffs were selected. Concentrates are the feedstuffs which contain less than $18 \%$ crude fibre and more than $60 \%$ Total Digestible nutrients. The concentrates are further classified as energy rich concentrates which contain more than $20 \%$ crude protein, and energy rich concentrates which have less than $20 \%$ crude protein. There are two main categories in energy rich concentrates; they are carbohydrates and lipids (oils and fats). As the carbohydrate source wheat was selected and as the lipid source palm oil was selected. Wheat was analyzed from three different countries; India, Australia and USA, representing Asian, Oceania, and North American regions respectively. Palm oil used for analysis, was imported from two countries; Malaysia and Indonesia, and both of them were from East Asian region.
\end{abstract}

From protein rich concentrates, soya bean meal was selected as the vegetable protein source while the fish meal was selected as the animal protein source. Soya bean meal was analyzed from three different countries; Brazil, USA, and India, representing South American, North American, and Asian regions respectively. Fish meal also was 
analyzed from three different countries; Denmark, Chili, and Maldives, representing European, South American, and Asian continents respectively.

Proximate analysis (Moisture, protein, fat fibre, ash, silica) was carried out for Soya bean meal, Fish meal, and Wheat. Starch and sugar contents were determined in wheat, and the soluble protein levels were determined in soya bean meal. Calcium, phosphorous, salt and pepsin digestibility values were obtained in fish meal. Palm oil was analyzed for general quality parameters of oil; namely, Impurity, Iodine value, Peroxide value, FFA, and Unsaponificable matter. For every parameter mentioned above, mean value of the replicate values were obtained. Metabolizable energy was calculated by prediction equations described by Janssen (1989).

Results were statistically analyzed using Minitab 17 software. In order to find out significant differences between data from different countries, One-way ANOVA test was applied (at $\alpha=0.05$ ). Grouping was done using the Fisher LSD Method and 95\% Confidence. According to the statistical analysis, there were significant differences present in the some quality parameters assessed between the countries from different regions as well as between the countries within the same region. This can be due to the biochemical and physical changes that occur during the development and processing stages of the feedstuff and on geochemical differences in the soil where the plants were grown. Variations in different regions may occur due to several reasons. Genetics, growing conditions, storage conditions and processes cause variations in composition and nutritional quality. 


\section{CHAPTER 1}

\section{INTRODUCTION}

Animal feed means any simple or compounded product intended to supply wholly or partly the nutritional requirements of animal or poultry and which on being fed to them contribute to their maintenance, growth and productive and includes feed additives.

Animal feed plays an important part in the food chain and has implications for the composition and quality of the livestock products (milk, meat and eggs) that people consume. Livestock production is growing rapidly worldwide, which is interpreted to be the result of the increasing demand for animal products. Overall, there has been a rise in the production of livestock products and this is expected to continue in the future. Specially, the poultry industry worldwide has seen significant developments in recent decades, following the increase in consumption of chicken by the population. In this scenario, the improvement in nutrition, genetics, health and management have allowed the continued development of this activity. However, to adequately meet the nutritional requirements, it is necessary to use diets that maximize the utilization of nutrients

Imported and local raw materials are used in animal feeds. Their quality is very important to produce a quality final product. By knowing the nutrient contents of raw materials, producers can identify the deficient nutrients that need to be supplemented. A firm understanding of categories of feeds and their role in feeding animals will make identifying alternatives easier. The diversity of foods and sub products used in feed formulation for poultry indicate the necessity of understanding their nutritional values, aiming its better utilization. The accuracy of the values of chemical composition, energy and digestibility of nutrients is essential to reducing costs and improving productivity. 


\section{CHAPTER 2}

\section{LITERATURE REVIEW}

\subsection{Components of Poultry Diets}

Poultry diets are composed primarily of a mixture of several feedstuffs such as cereal grains, soybean meal, animal by-product meals, fats, and vitamin and mineral premixes. These feedstuffs, together with water, provide the energy and nutrients that are essential for the bird's growth, reproduction, and health, namely proteins and amino acids, carbohydrates, fats, minerals, and vitamins. (Alvarenga et al., 2013). The energy necessary for maintaining the bird's general metabolism and for producing meat and eggs is provided by the energy-yielding dietary components, primarily carbohydrates and fats, but also protein.

Poultry convert feed into food products quickly, efficiently, and with relatively low environmental impact compared with other livestock. (Speedy,2003). The high rate of productivity of poultry results in relatively high nutrient needs. Poultry require the presence of at least 38 dietary nutrients in appropriate concentrations and balance (NRC, 1994). Criteria used to determine the requirement for a given nutrient include growth, feed efficiency, egg production, prevention of deficiency symptoms, and quality of poultry product. These requirements assume the nutrients are in a highly bioavailable form, and they do not include a margin of safety. Consequently, adjustments should be made based on bioavailability of nutrients in various feedstuffs. 
A margin of safety should be added based on the length of time the diet will be stored before feeding, changes in rates of feed intake due to environmental temperature or dietary energy content, genetic strain, husbandry conditions (especially the level of sanitation), and the presence of stressors (such as diseases or mycotoxins)

Poultry diets also can include certain constituents not classified as nutrients, such as xanthophylls (that pigment and impart desired color to poultry products), the unidentified growth factors claimed to be in some natural ingredients, and antimicrobial agents (benefits of which may include improvement of growth and efficiency of feed utilization). Each of these components of poultry diets is considered in the following sections.

\subsection{Energy}

Energy is not a nutrient but a property of energy-yielding nutrients when they are oxidized during metabolism. The energy value of a feed ingredient or of a diet can be expressed in several ways. Thus, a description is presented below of terminology associated with dietary energy values, including units of measure (digestible energy, metabolizable energy, etc.). The energy requirements of poultry and the energy content of feedstuffs are expressed in kilocalories ( $1 \mathrm{kcal}$ equals 4.1868 kilojoules).

\subsubsection{Energy Terminology}

Energy terms for feedstuffs are defined and discussed in detail in Nutrient Requirements of Poultry (NRC, 1994). 